\title{
Educación, exilio y diplomacia: Vasconcelos, Mistral, Torres Bodet y la proyección internacional de sus ideas educativas, 1921-1964*
}

\author{
Fabio Moraga Valle** \\ Recibido el 5 de junio de 2018; aceptado el 31 de agosto de 2018
}

\section{RESUMEN}

A partir de 1920 los gobiernos posrevolucionarios mexicanos pusieron en marcha una de las transformaciones más radicales que se hayan efectuado en el continente, la constitución de la Secretaría de Educación Pública, SEP, para alfabetizar a la gran masa campesina e indígena que permanecía en el analfabetismo. Este proceso reunió a tres intelectuales de envergadura: los mexicanos José Vasconcelos y Jaime Torres Bodet, y la chilena Gabriela Mistral. Éstos tuvieron una larga relación de amistad y colaboración que traspasó los cortos años de Vasconcelos a cargo de la SEP, los dos ministerios de Torres Bodet y su estancia en la UNESCO y la errancia diplomática y poética de Mistral. La relación que se mantuvo y fructificó pese a los exilios, los cargos diplomáticos y las vicisitudes políticas que enfrentaron, lejos de

* Este trabajo es parte del proyecto "Inclusión y exclusión social en el sistema educativo nacional. Organización cobertura y financiamiento, 1921-1964” que el autor desarrolla en la Coordinación de Humanidades de la UNAM. Una versión inicial fue presentada en el Coloquio Relaciones Históricas Chile-México, organizado por la Embajada de Chile y realizado en el Museo Nacional de Antropología, el 16 de noviembre de 2017 y otra, más acabada y sobre una base documental más completa, en el Coloquio: "Intelectuales y Exilio Iberoamericano”, en el Instituto de Investigaciones Histórico-Sociales de la Universidad Veracruzana, en Xalapa los días 15 y 16 de marzo de 2018. Quiero agradecer los comentarios de dos evaluadores anónimos que ayudaron a mejorar este artículo.

** Investigador Asociado, Coordinación de Humanidades, Universidad Nacional Autónoma de México, correo electrónico: fabiohis@gmail.com. 
ser meramente de amistad o de formal diplomacia, consolidó una colaboración que se mantuvo durante casi cuarenta años, influyendo en la formación de organismos internacionales como la UNESCO. Nuestra hipótesis es que, más allá de los cambios mundiales que se desarrollaron entre 1921 y 1964 y de los que experimentaron las concepciones políticas y pedagógicas de estos intelectuales, hay una idea central en el proyecto educativo que se impulsó en México, el cual constituye el aporte a la educación universal: la alfabetización de grandes masas excluidas para la inclusión en la nación y el desarrollo de una cultura para la paz.

Palabras clave: posrevolución, educación, diplomacia, UNESCO.

\section{Education, exile and diplomacy: Vasconcelos, Mistral, Torres Bodet and the international projection of its educational ideas, 1921-1964}

\section{AbSTract}

From 1920 the post-revolutionary Mexican governments set in motion one of the most radical transformations that have been made in the continent, the construction of the Secretariat of Public Education, SEP, to teach literacy to the large peasant and indigenous mass that remained in illiteracy. This process brought together three important intellectuals: the Mexicans José Vasconcelos and Jaime Torres Bodet and the Chilean Gabriela Mistral. These had a long relationship of friendship and collaboration that transcended the short years of Vasconcelos in charge of the SEP, the two ministries of Torres Bodet and his stay in UNESCO and the diplomatic and poetic wandering of Mistral. The relationship, which was maintained and succeeded despite the exiles, diplomatic positions and political vicissitudes faced by the three, far from being merely of friendship or formal diplomacy, consolidated a collaboration that lasted almost forty years, influencing the formation of international organizations such as UNESCO. Our hypothesis is that, beyond the global changes that took place between 1921 and 1964 and those that experienced the political and pedagogical conceptions of these intellectuals, there is a central idea in the educational project that was promoted in Mexico, which constitutes the contribution to universal education: the literacy of large masses excluded for inclusion in the nation the development of a culture for peace.

Key words: post revolution, education, diplomacy, UNESCO. 


\section{La CReación de la Secretaría de Educación Pública}

$\mathrm{D}$ espués del asesinato de Venustiano Carranza, en mayo de 1920, los diferentes grupos revolucionarios llegaron a un acuerdo provisorio para la sucesión presidencial. Con ello se inició la "posrevolución", etapa que se prolongó por varios años, hasta que se consolidó un nuevo régimen, después de casi 10 años de guerra civil, con la que se logró derrotar al Porfiriato: la oligarquía en el poder que había gobernado México entre 1876 y 1911. Los primeros gobiernos posrevolucionarios se caracterizaron por un consenso frágil, que sin embargo permitió el desarrollo de un proyecto de nación moderno, el cual mantuvo desacuerdos y fricciones entre los nuevos dueños del poder político: el grupo "sonorense".

El proyecto más importante que impulsó el nuevo Estado mexicano fue el educativo, que inició normalizando el funcionamiento de la Universidad Nacional para luego construir un sistema educacional moderno con el que, tal como lo había proyectado la Constitución de 1917, incluyera al 80\% de la población campesina e indígena analfabeta en la nación mexicana. Adolfo de la Huerta asumió el poder Ejecutivo desde el 1 de junio al 30 de noviembre de 1920; durante este interinato se colocó a la cabeza del proyecto educativo el abogado y filósofo José Vasconcelos, fogueado conspirador político y hombre con las apropiadas credenciales intelectuales para enfrentar tan difícil tarea. Egresado de la Escuela Nacional de Jurisprudencia, Vasconcelos había participado en la Sociedad de las Conferencias (1907) y luego en el mítico Ateneo de la Juventud (1909), dos “cenáculos” de jóvenes intelectuales que realizaron una dura crítica a la cultura del régimen de Porfirio Díaz, en el que predominaban las corrientes cientificistas y racionalistas. Los "ateneístas”, en cambio, cultivaron las corrientes antirracionalistas, intuicionistas, metafísicas y espiritualistas que se desarrollaban en Europa, Estados Unidos y algunos países del continente. ${ }^{1}$ Desde 1909 Vasconcelos se unió a

\footnotetext{
Vasconcelos recibió una buena educación primaria tanto en distintas ciudades mexicanas como en Eagle Pass, Texas; posteriormente emigró a la Ciudad de México donde estudió en la Escuela Nacional Preparatoria, y Leyes en la Escuela Nacional de Jurisprudencia. Formó parte de la "Generación del Centenario" junto con Antonio Caso, Alfonso Reyes, Martín Luis Guzmán y Pedro Henríquez Ureña, entre otros jóvenes intelectuales formados en las postrimerías del Porfiriato. Reconoció filas en el "antirreeleccionismo", movimiento político liderado por Francisco I. Madero en contra de la reelección de Porfirio Díaz para la Presidencia de la República. En 1920 formó parte del "Plan de Agua Prieta” en el que se alió con Álvaro Obregón para sacar a Venustiano Carranza del poder y donde Adolfo de la Huerta ejerció interinamente la presidencia. Así, en 1920, Vasconcelos era un intelectual con una sólida formación filosófica y jurídica y una vasta experiencia política como conspirador y
} 
Francisco I. Madero, con quien compartía inquietudes como el espiritualismo y la admiración hacia la cultura de la India ${ }^{2}$. Esta trama de influencias y contactos intelectuales se mantuvo durante varias décadas entre la élite política posrevolucionaria.

Desde la rectoría de la Universidad Nacional, Vasconcelos impulsó una fuerte campaña de alfabetización que convocó a la sociedad letrada para que colaborara con una obra de redención de las clases desposeídas con el fin de alfabetizarlas e incluirlas en la nación que había que construir después de la guerra revolucionaria. La inclusión de la población en la nación, a través de la enseñanza de la lectura, era un viejo problema pendiente desde la Independencia de las repúblicas hispanoamericanas, en las décadas de 1810 y 1820; pero México, comparado con el resto de América Latina, era uno de los más atrasados. Académicos, estudiantes universitarios, maestros normalistas, dueñas de casa, trabajadores de clase media y ciudadanos comunes fueron enrolados en brigadas alfabetizadoras que intentaron sacar a los iletrados de su condición de marginalidad y exclusión de la vida moderna.

La segunda etapa fue la creación de la Secretaría de Educación Pública, un ministerio que se encargara de las tareas que el Estado debía asumir para educar a sus ciudadanos, para lo cual el presidente Álvaro Obregón publicó el decreto de creación el 25 de julio de $1921^{3}$. Desde el comienzo, el proyecto despertó suspicacias entre los jefes de los poderes locales, gobernadores, hacendados, alcaldes, caciques, jefes militares, etcétera, —es decir, toda la "base social" del "antiguo régimen"- porque establecía la "federalización de la educación”, es decir, planteaba la centralización del organismo en el Estado federal, con el fin hacerlo más eficiente y abarcador. Para combatir estas resistencias y legitimar socialmente la nueva institución, Vasconcelos impulsó una fuerte campaña de propaganda para la cual se hizo acompañar de artistas e intelectuales que recorrieron el país promoviendo el proyecto. Pero también convocó a intelectuales latinoamericanos a colaborar con su campaña redentora. La invitada más famosa fue la poetisa y profesora primaria chilena Gabriela Mistral quien, pese a estar en ese país sólo dos años,

funcionario revolucionario. Véase Vasconcelos, Ulises criollo, y El Desastre, México, FCE, 1982.

2 El controversial y proteico pensamiento filosófico de Vasconcelos ha sido fruto de apasionados y críticos análisis a lo largo de los años. Particularmente polémicos - y a veces incomprendidos - han sido su intuicionismo y su espiritualismo, (este último compartido, por ejemplo, con Antonio caso), basado en las reflexiones de Bergson, Boutroux y Nietzsche, entre otros. Uno de los últimos trabajos precisamente sobre su intuicionismo en: Roberto Luquín Guerra, “La intuición originaria en la filosofía de José Vasconcelos”, Signos Filosóficos, VIII: 16, julio-diciembre, 2006, pp. 97-124.

3 Fell, José Vasconcelos. Los años del águila, México, UNAM, 1987, p. 67. 
entre julio de 1922 y julio de 1924, tuvo una fuerte influencia en el impulso inicial y el desarrollo posterior del sistema educativo ${ }^{4}$.

En el presente artículo vamos a analizar la colaboración entre Gabriela Mistral, José Vasconcelos y su continuador, Jaime Torres Bodet en el proyecto educativo posrevolucionario que tenía por objetivo integrar a la nación a quienes, por su analfabetismo, estaban excluidos y habían alimentado los casi 10 años de guerra revolucionaria. Analizaremos históricamente tanto la información de diversos fondos documentales existentes en México, Chile y París, como publicaciones periódicas y textos escritos por nuestros autores; una nota especial merece la correspondencia intercambiada entre ellos, que nos ha revelado una faceta hasta ahora desconocida de su prolongada comunicación a lo largo de los años y la geografía. Nuestra hipótesis es que, más allá de los cambios históricos mundiales que se desarrollaron entre 1921 y 1964 y de los que experimentaron las concepciones políticas y pedagógicas de estos intelectuales, hay una idea central en el proyecto educativo que se impulsó en México y en el que participó Gabriela Mistral, que constituye el aporte a la educación universal: la alfabetización de grandes masas excluidas para la inclusión en la nación y el desarrollo de una "cultura para la paz".

\section{UNA NORMALISTA CHILENA EN VIAJE HACIA MÉXICO}

En el otro extremo de América Latina, una poetisa y maestra normalista autodidacta, se había hecho famosa desde que ganó los Juegos Florales de 1914, con sus trágicos poemas Los sonetos de la muerte. Desde entonces recorrió un difícil periplo dificultado por las reglas de la burocracia educacional chilena que la enviaba a los lugares más recónditos y menos deseados por los profesores, a hacerse cargo de la educación de niños y niñas campesinos y pobres. Lejos de amilanarse por las cortapisas burocráticas, la joven maestra autodidacta fue concibiendo una refinada concepción de la educación campesina y popular que combinaba sus intuiciones y expe-riencias con nuevas teorías educativas que recién estaban ascendiendo ante las limitaciones de las pedagogías tradicionales y entre cuyos teóricos preferidos estaban los escritores León Tolstoi y Rabindranath Tagore. Lo mismo sucedió con su pensamiento político: fue fruto de sus experiencias y lecturas propias y no de una educación formal escolar o universitaria. Todo ello la colocó lejos de los lugares comunes del stablishment cultural y político del Chile de principios de siglo Xx, lo que conllevó dificultades y desencuentros con la élite social y

4 Moraga, "Lo mejor de Chile está ahora en México. Ideas políticas y labor pedagógica de Gabriela Mistral en México, 1922-1924”, Historia Mexicana, núm. 251, México, El Colegio de México, 2014, pp. 1181-1248. 
política de la época a medida que, contradictoriamente, su fama y reconocimiento se elevaban fuera de su país.

Desde la muerte del poeta Amado Nervo en 1919, entonces embajador en Buenos Aires y con quien sostuviera una amistad epistolar, Gabriela se acercó a México y sus intelectuales, en especial a quienes eran los más altos representantes de esa cultura. El mismísimo Vasconcelos, Antonio Caso, y el embajador y poeta Enrique González Martínez, fueron motivo de halagüeñas reseñas a sus producciones literarias y filosóficas y de un nutrido intercambio de cartas y de la colaboración en El Maestro, la revista por antonomasia del vasconcelismo educativo. ${ }^{5}$ Este último fue quien recomendó al autor de Estudios Indostánicos que la contratara para apoyar su proyecto educacional. Gabriela ya había emprendido el viaje cuando Vasconcelos llegó a Chile en ese periplo que luego inmortalizara en La Raza Cósmica. Ya en el país y luego de los intercambios protocolares y diplomáticos, el filósofo de la revolución chocó con el stablishment cultural chileno, el ambiente militarista y la supremacía oligárquica en todos los espacios culturales ${ }^{6}$. Uno de esos tensos momentos fue una entrevista con el presidente de la República, el liberal Arturo Alessandri Palma; éste le criticó que no contratara a otras chilenas formadas en las instituciones oficiales. La respuesta del ateneísta —que no se dejó esperar, ni fue diplomática - fue remitida en un telegrama al presidente Obregón: "Más convencido que nunca de que lo mejor de Chile está ahora en México". ${ }^{7}$

El barco que la llevó al país revolucionado recaló antes en La Habana donde se le recibió apoteósicamente. Pedro Prado, ex dirigente estudiantil y consagrado poeta chileno, escribió a los poetas de México: "No hagáis ruido en torno a ella, porque viene en batalla de sencillez" ${ }^{8}$. El vapor Orcona llegó al puerto mexicano de Veracruz el 28 de julio de 1922. Allí la esperaban dos jóvenes intelectuales: Palma Guillén, quien sería su secretaria particular y amiga por el resto de su vida, y Jaime Torres Bodet, secretario particular del ministro Vasconcelos y luego director del Departamento de Bibliotecas de la

5 El maestro tenía un tiraje de 60.000 ejemplares y era distribuida gratuitamente entre los profesores mexicanos. Una investigación sobre esta revista en: Cantón Arjona, y Aguirre Beltrán: Revista El Maestro (1921-1923), Morelia, Instituto Michoacano de Ciencias de la Educación, 1997.

6 En ediciones de La Raza Cósmica, posteriores a la primera de 1925, Vasconcelos suprimió el capítulo sobre Chile por el rechazo que recibió de parte de la élite chilena. Vasconcelos, La Raza Cósmica, Misión de la raza iberoamericana. Notas de viajes a la América del Sur, París, Agencia Mundial de Librería, 1925.

7 Moraga, "Lo mejor de Chile está ahora en México”, p. 1181.

8 Prado, "Gabriela Mistral en La Habana. A los poetas de México", Repertorio Americano, núm. 23, San José, 21 de agosto de 1922, p. 313. 
SEP y con quien también cultivaría una amistad reforzada por la extensa labor educacional de ambos hasta poco antes de su muerte.

Al poco tiempo de llegar a la Ciudad de México, el gobierno le puso su nombre a una escuela-hogar femenina, la que se inauguró con gran pompa:

En el estrado de honor, que se levantó en el sitio donde se desarrolló el programa de la fiesta, se colocó entre las banderas de Chile y México, un escudo nacional, que rodeaban otras banderas de los países de la América Española. Los demás salones lucían guirnaldas de flores y plantas de sombra; y en estos distintos departamentos se instalaron los objetos artísticos y trabajos manuales que se hacen en el establecimiento, y que en su conjunto formaban una magnífica exposición. ${ }^{9}$

La poetisa y maestra, impresionada, respondió así al impresionante homenaje que por primera vez le brindaba un país que no era en el cual había nacido:

Así decía esta tierra a la desconocida mujer del sur: [...] Te damos una escuela industrial. Aunque has vivido muchos años para el pensamiento, has aprendido en la madurez de la vida que el trabajo material era tanto o mayor nobleza que aquél y que la América industrial salvará de muchas humillaciones a la América política. ${ }^{10}$

Gabriela Mistral había nacido en Vicuña, en el Valle del Elqui, en el desierto del norte de Chile, fue autodidacta y se formó con lecturas propias, de allí que valorara más las bibliotecas que las mismas escuelas, aunque, por su origen, su modelo preferido era la escuela rural y, en especial, las femeninas. Al igual que su pensamiento pedagógico, elaboró su pensamiento político a partir de sus experiencias y lecturas propias, no de una educación formal. En otros trabajos hemos establecido que su pensamiento se dividía en dos vertientes: una "conservadora" que valoraba la familia y el rol tradicional de la mujer como madre, esposa y educadora y otra "progresista" que se expresaba en un antioligarquismo, que destacaba el antimilitarismo. ${ }^{11}$ Pero hay más elementos, en la primera vertiente está el papel del "líder" intelectual: el conductor de grandes masas de seres humanos que se echaba

9 “Gabriela Mistral en México”, Repertorio Americano, núm. 23, San José, 21 de agosto de 1922, p. 315.

10 Archivo de la Secretaría de Educación Pública, ASEP, "Expediente personal de Palma Guillén Sánchez”, No 7634, 13 de julio de 1922, p. 255.

11 Moraga, “Lo mejor de Chile está ahora en México”, p. 1205. 
en los hombros la responsabilidad de conducir a su sociedad (papel en el que encajaba perfectamente Vasconcelos). En una segunda vertiente estaba el agrarismo, la concepción de que en América Latina la democracia sólo se podría construir con la subdivisión de la gran propiedad agrícola y la formación de una extensa red de pequeños y medianos productores de la tierra. En un artículo de 1928, escrito después del asesinato del ex presidente Obregón, Mistral se declaraba simpatizante de una reforma agraria sin violencia política que, de no hacerse, desataría un movimiento parecido al encabezado por el asesinado líder más radical de la revolución:

Entonces él va a moverse. A su manera, a la chilena, que los patrones parecen no conocer todavía. De un solo empellón y mortal. El “empellón” se llamó en México Emiliano Zapata y sus morelenses: saqueó, quemó, mató y repartió el suelo, todo a la misma hora. ${ }^{12}$

A su agrarismo agregó el sufragismo, es decir, la demanda del voto femenino y un fuerte antimilitarismo tanto por su experiencia chilena como lo que observó en México posteriormente. ${ }^{13}$ Con este bagaje intelectual y político llegó Gabriela Mistral a México a colaborar con el proyecto vasconcelista de educación, pero también a convivir con su intelectualidad y a hacer propaganda en su país de origen, al gobierno de Álvaro Obregón.

\section{UNA ESCUELA TOLSTOIANO-TAGOREANA MODELO REVOLUCIONARIO}

Uno de esos artículos de propaganda de la revolución educativa mexicana fue sobre otra escuela, creada en la misma Ciudad de México, a pocas cuadras del Palacio Nacional, la Escuela-Granja Francisco I. Madero. ${ }^{14}$ Esta escuela sobre la que Gabriela Mistral escribiera con tanto agrado no ha sido del todo comprendida, como tampoco el proceso general de establecimiento

12 Mistral, “Agrarismo en Chile”, Repertorio Americano, núm. 22, San José, 8 de diciembre de 1928, pp. 337-338.

13 Uno de los posicionamientos más fuertes en torno al sufragismo fue el prólogo al libro de Eduardo Frei Montalva, publicado en 1946. En él Gabriela no se guardó las críticas hacia el joven político, quien excluyó a las mujeres de su ensayo. Gabriela Mistral, "Prólogo" a Frei, La Política y el espíritu, Santiago, Editorial del Pacífico, 1946.

14 Mistral, "Cómo se ha hecho una escuela-granja en México", El Mercurio, Santiago, 1923. Entre otros Gabriela escribió sobre la educación posrevolucionaria: "La Reforma educacional en México”, El Mercurio, Santiago, 1925. 
de un sistema educativo, basada en las pedagogías de los escritores e intelectuales León Tolstoi y Rabindranath Tagore, e implementado experimentalmente allí. Trabajos "clásicos" como el de Meneses Morales han contribuido más a la confusión que a la compresión de su verdadero carácter y el alcance que tuvieron sus métodos y experimentos. Lo mismo ha pasado con trabajos más recientes como el de la británica Patience Schell que la caracteriza erróneamente como una "escuela industrial"; también fue definida como una escuela de la "pedagogía de la acción” por la antropóloga Eulalia Guzmán. En la década de 1930 su director la presentó como "la escuela" de la Revolución Mexicana o la escuela de la "educación socialista", promovida por el gobierno de Lázaro Cárdenas. ${ }^{15}$ Pero ¿Qué era realmente "La Madero”?

La Escuela Francisco I. Madero fue la escuela-granja de la que la SEP de Vasconcelos ensayó una serie de experimentos educacionales inspirados en las nuevas pedagogías, que efectuaron Oropeza y sus discípulos: paidocentrismo, fomento a la publicación de periódicos escolares, escuelas al aire libre, enseñanza intuitiva por medio de la agricultura, huertos escolares, rotación de suelos, cooperativas de producción, selección de semillas, enseñanza de conceptos básicos de organización y administración, etcétera, y los aplicó en la mayoría de las escuelas rurales y muchas urbanas que implementó a partir de $1923 .{ }^{16}$ La labor de esta escuela experimental sirvió para convencer a Vasconcelos de las bondades de la "escuela nueva o de la acción”, e impulsarla como la política educacional del Estado mexicano. ${ }^{17}$ Ese

${ }^{15}$ Meneses, Tendencias educativas oficiales en México 1911-1934, México, Universidad Iberoamericana, 1986; Schell, Church and state education in revolutionary Mexico City, Tucson, University of Arizona, 200 y Guzmán, La escuela nueva o de la acción, México, Editorial Cultura, 1923 y Ávila, La Escuela Francisco I. Madero y la educación en México, México, Talleres Gráficos La Nación, 1940.

${ }^{16}$ Aunque la existencia de "escuelas-granja” y de la educación agrícola en México es de larga data, algunos investigadores la remontan a los años posteriores a la Independencia, pocos proyectos recibieron el apoyo sostenido y fueron tan importantes y radicales como el de La Madero. La principal característica de la "escuela nueva o de la acción” era el "paidocentrismo", el principio de centralidad del niño en el proceso educativo; por el contrario, la educación tradicional aplicaba el magistocentrismo, es decir, la centralidad del profesor en dicho proceso. Moraga, “¿Una escuela tolstoiana para la revolución mexicana? La EscuelaGranja Francisco I. Madero de la Colonia La Bolsa, 1921-940”, Pacarina del Sur 8:32, julio septiembre de 2017.

$<$ www.pacarinadelsur.com/index.php?option=com_content\&view=article\&id=1490\&catid=10>. Un resumen sobre la enseñanza agrícola en: Gómez, "Escuelas y enseñanza agrícola en Jalisco, 1920-1924”, X Congreso Nacional de Investigación Educativa, <http://www.comie.org.mx/congreso/memoriaelectronica/v10/pdf/area_tematica_09/ponenc ias/1407-F.pdf $>$.

17 SEP, Bases para la organización de la escuela primaria, conforme al principio de la acción, México, talleres de la impresora, 1923. 
año, cuando el Congreso de la República aprobó la nueva ley de educación dijo estas palabras a la prensa:

Las exposiciones de las escuelas de toda la República, verificadas a fin de año, convencieron aún más a los escépticos de la conveniencia de educar a los niños desde la infancia, en ocupaciones útiles y productivas. El éxito de la llamada Escuela de la Acción es tan notorio, que ya no se discute. Lo que más sorprende es el talento con que los más humildes maestros de escuela supieron poner en práctica las nuevas enseñanzas, habiendo contado solamente con orientaciones generales, y con ninguna ayuda en materia de fondo. ${ }^{18}$

Tres años después de iniciada la primera campaña alfabetizadora y de reorganizada La Madero, en diciembre de 1922, Gabriela Mistral, entonces funcionaria del Gobierno de México visitó la escuela, por encargo de Vasconcelos. El barrio La Bolsa estaba a pocas cuadras al norte del centro de la Ciudad de México, donde primaban los palacios dieciochescos y los fastuosos edificios porfirianos. Un sentimiento de extrañeza asaltaba el pensamiento de la profesora ¿Por qué el intelectual mexicano quería que ella viera precisamente esa escuela?, “¿Para qué — se decía a sí misma— traerán a ver un colegio tan pobre a una extranjera?”, si normalmente se le muestra al visitante los palacios, las casas señoriales... los jardines suntuosos. Al poco tiempo de estar entre niños pobremente vestidos y hombres humildes, la poetisa comprendió la curiosidad que asaltaba al autor de Estudios Indostánicos: "Tenía delante de mí realizada en tierra mexicana la escuela que soñó León Tolstoi y que ha hecho Tagore en la India: la racional escuela primaria agrícola, que debiera formar el ochenta por ciento de los colegios en nuestros países”. ${ }^{19}$ ¿Cuál era esa pedagogía y esa escuela que la hacen tan importante para Vasconcelos, Mistral y la SEP?

18 "Por falta de dinero será muy exigua la educación. El ministro Vasconcelos hace declaraciones sobre la situación del ramo a su cargo, y justifica que no pueda desarrollarse ningún plan sobre instrucción pública”, Excélsior, México, 17 de enero de 1924, Boletín de la Secretaría de Educación Pública, tomo II, núm. 5 y 6, 2º semestre de $1923-1^{\circ}$ semestre de 1924, p. 655. Por el contrario, la investigadora Alicia Civera sostiene que Vasconcelos tenía "objeciones" hacia la escuela de la acción, lo cual se contradice con todo lo que hemos planteado. Cfr. Civera, La escuela como opción de vida. La formación de maestros normalistas rurales en México, 1921-1945, Toluca, El Colegio Mexiquense, 2013, p. 45.

19 Mistral, ¿Cómo se ha hecho una escuela-granja en México?, en Zegers, Gabriela y México, Santiago, RIL Editores, 2007, pp. 55-63. 


\section{UNA ESCUELA EXPERIMENTAL, MODELO DE LA EDUCACIÓN REVOLUCIONARIA MEXICANA}

En 1920 un niño descalzo, andrajoso y hambriento, entró a estudiar a una escuela pobre y marginal de la Colonia La Bolsa en la Ciudad de México. Ésta había sido fundada por el presidente de México y líder de la Revolución antiporfirista, Francisco I. Madero, nueve años atrás y atravesado las vicisitudes de la ciudad durante la ocupación de los distintos ejércitos revolucionarios. El futuro del niño, quien se llamaba José Ávila Garibay, no era prometedor: la escuela no tenía los implementos mínimos para impartir clases y el barrio en el que estaba emplazada tenía fama de ser un nido de delincuencia a la que incluso pertenecían los mismos estudiantes.

Pocos años antes, la Casa del Obrero, una organización de trabajadores derivada de la anarquista Casa del Obrero Mundial, que tenía su sede en la Colonia La Bolsa, tomó la escuela a su cargo. La organización la puso bajo la dirección de Arturo Oropeza, maestro normalista, quien junto a otros 12 jóvenes profesores oriundos de Baja California, se dio a la tarea de levantarla de su deplorable estado. Además, Oropeza se inscribió como maestro alfabetizador en la campaña que, desde la Universidad Nacional, era liderada por el rector Vasconcelos. No paró allí el impulso del normalista y, alrededor de 1920, transformó a "La Madero" en una escuela-granja. Los niños del barrio empezaron a llegar, recelosos, a asistir a las clases en improvisadas salas sucias y derruidas. Al poco tiempo el maestro puso en marcha su experimento tolstoiano y tagoreano: los llevó a cultivar las dos hectáreas del terreno aledaño que había conseguido en donación y que antes eran ocupados para fiestas populares que derivaban en juergas y bandidaje. Los niños cultivaron con entusiasmo las pequeñas parcelas y cuando obtuvieron los frutos de la tierra, los llevaron al mercado. Pero de regreso Oropeza vio la desilusión en sus ojos: no habían conseguido una suma decente de la venta de las hortalizas. ${ }^{20}$ Entonces surgió la idea (u Oropeza la incentivó), de vender colectivamente la producción y a su vez separar el dinero en tres partes: una para comprar semillas y herramientas, otra para el ahorro y una tercera de ganancia para cada uno de ellos; establecieron un lema "Trabajo y más trabajo” y se organizaron en cooperativas de producción y consumo. Los estudiantes emprendieron, entre otras, campañas de limpieza de su colonia para erradicar las basuras y las plagas de roedores. No sólo se implementaron técnicas modernas y experimentales de cultivo; cuando se les agotaron las dos hectáreas que el municipio les había dado a concesión, utilizaron el

20 Mistral, “Cómo se ha hecho una escuela-granja en México”, en Zegers, Gabriela y México, p. 59. 
canal que pasaba por detrás del terreno y construyeron las tradicionales chinampas, donde siguieron cultivando, experimento al que llamaron "Xochimilquito". Con la guía indirecta de sus maestros, la organización de los jóvenes creció y se fortaleció e, imitando los experimentos de Rusia y la India, encabezados por las escuelas experimentales de Yásnaia Poliana y Shantiniketan, en 1923 el estudiante José Ávila organizó un periódico infantil, El niño agricultor. Con existencia legal y alguna subvención económica, más el apoyo de los maestros normalistas de la escuela, alcanzó a publicar al menos 10 números. ${ }^{21} \mathrm{El}$ apoyo de la Secretaría hacia la escuela se incrementó, por ejemplo, a través de la distribución de desayunos escolares, programa a cargo de la radical maestra Elena Torres. ${ }^{22}$

El 17 de octubre de 1923 Vasconcelos aprobó el Plan de las Misiones Federales de Educación, que le presentó José Gálvez, diputado agrarista al Congreso de la Unión por el XXII distrito de Puebla. Mistral colaboró en la elaboración del proyecto; el informe, que firmaba el ministro, incluyó observaciones de la poetisa orientadas al indígena y a los misioneros: la enseñanza de educación cívica "para que el indio conozca el sitio y la situación que tiene como ciudadano" la enseñanza "intuitiva" acerca de las "grandes civilizaciones autóctonas (mayas, toltecas, etcétera) con el objeto de formar en esta gente deprimida, humillada, el orgullo de su gran pasado, para ennoblecerlos a sus propios ojos, para borrar su dejo de esclavos”, y la acción del Estado orientada a lograr una mejor comunicación entre el maestro y la comunidad para que se convirtiera en "el guía moral de los indios". ${ }^{23}$

Antes de que se aprobara la ley específica el Departamento de Educación y Cultura Indígena, DECI de la SEP, convocó a un Congreso de Maestros Misioneros que se celebró entre septiembre y octubre de 1922 en la Ciudad de México. En la inauguración estuvieron presentes 92 maestros misioneros, el secretario Vasconcelos, el subsecretario Francisco Figueroa, el profesor Lauro G. Caloca jefe de la DECI. Gabriela Mistral fue nombrada presidenta honoraria y después de su discurso, donde habló como maestra rural, llegó hasta el evento a una comisión de niños de La Madero. Mistral volvió a

21 Moraga, “¿Una escuela tolstoiana para la revolución mexicana? El experimento editorial infantil de La madero difería de los de Shantiniketan y Yasnaia Poliana; éstos eran mucho más autogestionados: Los periódicos de los niños bengalíes eran escritos a mano y los de Tula sólo tenían circulación interna.

22 Ávila, La escuela Francisco I. Madero y la Educación en México, México, talleres Gráficos de la Nación, 1940, p. 33.

23 "Proyecto para la organización de las misiones federales de educación”, leído ante la Cámara de Diputados. Primera Comisión de Educación Pública, septiembre de 1923. Sierra, Las misiones culturales, México, Secretaría de Educación Pública, 1973, p. 93. Véase, también: “Una carta de la señorita Gabriela Mistral”, Boletín de la Secretaría de Educación Pública, tomo II, núm. 5 y 6, 1923-1924, pp. 598-599. 
tomar la palabra para hacer notar a los congresistas el carácter único de esta institución. Enseguida intervino el estudiante José Ávila, quien presidía la Liga Escolar de Hortelanos y les recomendó a los asistentes: “...que vieran en la tierra el porvenir de la Patria”. ${ }^{24}$

Este exitoso experimento educacional llevó a las autoridades de la SEP a intentar replicarlo en distintos estados del país, si en la misma Ciudad de México se podía establecer una escuela agrícola que se transformara en ejemplo de organización, no sólo educacional sino también social, la utopía agrarista podía realizarse en el campo mexicano y con ello poner fin a la violencia rural. La misma Gabriela Mistral encabezó la fuerte campaña de propaganda de la SEP, para lo cual viajó personalmente a las comunidades y habló directamente con campesinos e indígenas. ${ }^{25}$ Así, de esta escuela y sus experimentos educativos nacieron las normales rurales, las Casas del Pueblo, las misiones culturales y todos los intentos por alfabetizar a campesinos e indígenas y hacer productiva la tierra.

\section{EDUCACIÓN Y ESTADO POSREVOLUCIONARIO}

Los regímenes de Plutarco Elías Calles, del "maximato" (1928-1934) y el de Lázaro Cárdenas (1934-1940) desarrollaron un lento e intrincado camino hacia la "desruralización" de la educación en México y fomentaron el industrialismo y el desarrollo de los sindicatos. Ello significó abandonar las propuestas espontaneístas, intuicionistas, improvisadoras y humanistas, y fomentar el desarrollo y fortalecimiento del sistema educativo por medio de la creación de escuelas técnicas e industriales y el fomento de una mayor productividad del mundo campesino e indígena, por medio de la planeación. Ello implicó abandonar la alfabetización como forma de inclusión en la sociedad y fomentar el trabajo agrícola y la producción industrial.

Este enorme esfuerzo tuvo poco éxito durante el período entre 1924 y 1940, y en el fondo las directrices diseñadas por Vasconcelos y sus seguidores, reunidas en la ecléctica definición de "Escuela nueva o de la acción”, se siguieron aplicando en el sistema educativo ya que el Estado no tenía la suficiente capacidad para llevar a cabo las políticas oficiales ni económica, ni administrativamente. Además, el callismo y el maximato combatieron al vasconcelismo educativo y con ello perdieron el enorme aparato de propa-

24 “Discurso de la señorita Gabriela Mistral”, Archivo de la Secretaría de Educación Pública, ASEP, exp. 21 f. 4.

${ }^{25}$ Por ejemplo, en el momento de escribirle a Gálvez sobre el proyecto de las misiones, Gabriela se encontraba en el Mineral del Chico (¿Zacatecas?). Véase "Una carta de la señorita Gabriela Mistral”, pp. 598-599. 
ganda formado por los intelectuales de primera línea, que fueron reemplazados por segundones o burócratas. En los años siguientes se profundizó la distancia entre la élite del sistema educativo, radicada en la Ciudad de México, quienes generaban las directrices y elaboraban los planes de estudio y los libros de texto; los directores de escuelas, a cargo de implementar dichos planes y los maestros rurales que los aplicaban. Es imaginable que esa distancia se volvió sideral durante los tres años de la Guerra Cristera, donde la Iglesia derrotó ideológicamente al Estado Callista y lo separó de las comunidades campesinas.

A diferencia de burócratas capitalismo, e incluso de los directores de escuela, los maestros rurales constituyeron un auténtico movimiento popular, formado entre los últimos años del Porfiriato y los años de lucha revolucionaria, por profesores rurales y urbanos, quienes implementaron la construcción de escuelas por la comunidad, el desarrollo de las huertas escolares, la educación al aire libre (cuando aún no se habían construido las escuelas), la improvisación de espacios de enseñanza y la aplicación, muchas veces intuitiva e improvisada, de los planes de estudio que se elaboraban en el centro del país. ${ }^{26}$ Por mucho que se le combatiera, el vasconcelismo educativo siguió vivo en las comunidades y escuelas rurales. Cuando se supo de la muerte de Gabriela Mistral, Palma Guillén relata lo que aconteció en los pueblos, más de treinta años después de su corta e intensa estadía: "Cuando murió, de muchos de esos pueblos, recibí yo cartas de pésame de personas que, 35 años antes, la habían conocido y que me escribieron a mí porque no sabían si ella tenía aún familia”. ${ }^{27}$

Hacia 1958, cuando el sistema llevaba más de tres décadas de instalado, la distancia entre la SEP y el número creciente de escuelas se había incrementado, como consecuencia de la federalización ideada por Vasconcelos, pero sobre todo por la unificación sindical. ${ }^{28}$ La presencia de inspectores cuya lealtad estaba más con el Sindicato Nacional de Trabajadores de la Enseñanza, SNTE, que con el organismo gubernamental contribuyó a desinformar al Estado de la real situación de la educación primaria a nivel nacional. De esta manera, muchas de las iniciativas planeadas y elaboradas por la Secretaría en la Ciudad de México no se implementaban en los estados y

26 En sus memorias el mismo Torres Bodet analiza las deficiencias que hemos señalado, "Plan de Once Años", Memorias, p 78-79. Hemos tratado con mayor detención estos aspectos en Moraga "Las ideas pedagógicas de Tolstoi y Tagore en el proyecto vasconcelista de educación, 1921-1964, Historia Mexicana, núm. 259, México, El Colegio de México, 2016, pp. 1341-1404.

27 Guillén, “Gabriela Mistral, 1922-1924”, Lecturas para mujeres, México, SEP, 1988, p. IX.

28 Greaves, Del radicalismo a la unidad nacional: una visión de la educación en el México contemporáneo 1940-1964, México, El Colegio de México, 2008, p. 87. 
especialmente en las zonas rurales a donde estaban destinadas, y la improvisación y la intuición siguieron siendo las herramientas más recurridas por los maestros a la hora de enseñar a los estudiantes.

Así, tanto la importancia de la escuela nueva, de la educación agrícola, como de la centralidad del niño, fueron elementos que tensionaron las relaciones y debates entre los educadores mexicanos de la primera mitad del siglo XX, cuando desde el Estado Federal se intentaba imponer otros modelos educativos.

\section{MisTRAL, TORRES BODETY LA INTERNACIONALIZACIÓN DEL MODELO EDUCATIVO MEXICANO}

Vasconcelos renunció a la dirección de la SEP en julio de 1922, en solidaridad hizo lo mismo Gabriela Mistral quien se declaró a sí misma como una "chilena errante": ya no volvería a su país salvo en dos breves ocasiones. Ambos iniciaron un camino que los llevó a revisar sus certidumbres políticas y sus concepciones pedagógicas. En 1935 el ateneísta escribió De Robinson a Odiseo, pedagogía estructurativa, donde se distanció de la pedagogía tolstoiana y criticó la educación basada en las ideas de Rousseau. ${ }^{29}$ Gabriela, por su parte, apoyó a su amiga y secretaria Palma Guillén en su carrera al interior de la diplomacia, bajo el régimen de Plutarco Elías Calles (19241928), lo que la puso en contra de la opinión de Vasconcelos, viejo enemigo del presidente. Mientras Vasconcelos desarrolló una conflictiva y variante relación con el Estado mexicano, Gabriela se autoexilió, aunque desarrolló una fuerte carrera diplomática.

La relación de México con la comunidad internacional en el ámbito educativo se había iniciado con el gobierno de Álvaro Obregón, y Gabriela Mistral fue parte de ese proceso. Al poco tiempo de dejar su cargo en la SEP, la poetisa se vinculó al Instituto Internacional de Cooperación Intelectual, IICI, un organismo internacional de la Sociedad de Naciones, surgida a partir de 1918, una vez finalizada la Gran Guerra europea. En la primera reunión, celebrada en noviembre de 1920, se discutió la necesidad de establecer la "cooperación intelectual" junto a la actividad política de los Gobiernos. ${ }^{30}$ En la Asamblea del 13 de diciembre de ese año se envió una

29 Vasconcelos, De Robinson a Odiseo, pedagogía estructurativa, Madrid, 1935.

30 Con esta iniciativa competía con la convocatoria que hicieron los intelectuales franceses Anatole France y Henri Barbuse cuando, mediante el manifiesto "El resplandor en el abismo, lo que quiere el grupo Claridad”, France y Barbusse llamaron a formar una internacional del pensamiento (cercana, pero distinta de la III Internacional Comunista) con el fin de 
propuesta para establecer la Organización Internacional del Trabajo Intelectual. La Asamblea acordó preparar un informe sobre la utilidad que tendría la existencia de un organismo técnico de educación en la Sociedad de Naciones. ${ }^{31} \mathrm{El} 4$ de enero de 1922 se decidió la creación de la "Comisión Internacional de Cooperación Intelectual”, integrada por trece miembros, que se reunió por vez primera en Ginebra el 1 de agosto de 1922 y eligió como Presidente al francés Henri Bergson. Hemos visto que este filósofo espiritualista y vitalista era ampliamente conocido por la intelectualidad antioligárquica latinoamericana y especialmente por José Vasconcelos y Gabriela Mistral. ${ }^{32}$

En el IICI Gabriela adquirió una gran experiencia diplomática y de promotora cultural donde hizo de "puente" entre México y Chile, para fortalecer la cultura hispanoamericana. En 1933, fue nombrada "cónsul vitalicio" por el gobierno de su país, con el privilegio de poder elegir la ciudad para ejercer su puesto; paralelamente, Jaime Torres Bodet apoyó la publicación de un libro de folklore chileno que patrocinaba Gabriela. La poetisa no dudó en solicitar la colaboración del joven diplomático mexicano; éste le devolvió la gentileza confiando su representación personal cuando los compromisos hacían imposible estar al mismo tiempo en dos lugares distintos del mundo. ${ }^{33}$ Diez años después su labor continuaba: José Santos González Vera, editor de la Universidad de Chile, miembro de la Cooperación Intelectual y amigo de la poetisa, le escribió comparándola con Simón Bolívar, por su intento de unir culturalmente a los países del continente y solicitándole información sobre la música popular española. ${ }^{34}$

La relación de Gabriela con México, a través de la educación, continuó por muchos años, pese a la distancia y a las enfermedades que la aquejaron

aunar voluntades entre los intelectuales del mundo que estuvieran a favor de la paz y contra una nueva conflagración mundial.

31 Sobre la Cooperación intelectual véase Pita, Educar para la paz. México y la cooperación intelectual internacional, 1922-1948, México, Universidad de Colima-Secretaría de Relaciones Exteriores, 2014 y Herrera, "México y el Instituto Internacional de Cooperación Intelectual 1926-1939”, Tzintzun, núm. 49, Morelia, enero-junio, 2009.

32 Valderrama, “La UNESCO y la Educación”. Para los nexos entre Bergson y el intelectual mexicano: Romanell, “Bergson in México: A Tribute to José Vasconcelos”, Philosophy and Phenomenological Research, vol. 21, núm. 4 (junio, 1961), pp. 501-513 y Luquín Guerra, "La intuición originaria en la filosofía de José Vasconcelos”, pp. 97-124.

33 En 1933 Gabriela Mistral estaba en la Universidad de Puerto Rico, en Río Piedras, entonces no dudó en solicitar al joven embajador mexicano en París la representara en una reunión de la Cooperación Intelectual que demandaba su presencia. "Carta Jaime Torres Bodet a Gabriela Mistral”, París, 10 de julio de 1933, AE, Santiago, exp. 8337.

34 José Santos González Vera a Gabriela Mistral (esquela), Santiago, 18 de diciembre de 1943, “Comisión Chilena de Cooperación Intelectual. Universidad de Chile”, AE. <http://www.bibliotecanacionaldigital.cl/bnd/635/w3-article-151822.html>. 
con la edad. Desde su colaboración en el proyecto vasconcelista buscó influir en el debate educacional de su país a través de artículos de prensa y cartas dirigidas a amigos y colegas de profesión, así como funcionarios influyentes, donde hacía notar tanto sus concepciones previas, como aquéllas adquiridas en su "experiencia mexicana". ${ }^{35}$ En 1924, compiló su libro Lecturas para mujeres, por encargo del secretario de Educación, en el que reunió una selección muy personal de poemas y escritos de la literatura universal dedicada a las mujeres obreras de la escuela que llevaba su nombre. Entonces escribió también a favor de un cambio en los programas de estudios de las niñas de educación secundaria en Chile, en los momentos que las movilizaciones del magisterio chileno abogaban por introducir la "Escuela Nueva”. ${ }^{36}$ Años más tarde, y ya fuera de México, escribió en contra del Estado docente, por los peligros que éste tenía en manos de una oligarquía o de un régimen comunista; en este aspecto tenía los ejemplos de su propio país, donde el Partido Radical controlaba el aparato educacional desde fines del siglo XIX y en más de una oportunidad sus militantes, hombres y mujeres, obstaculizaron su carrera docente. También tenía la reciente experiencia en México donde el régimen de Plutarco Elías Calles (1924-1930), no sólo entró en conflicto con la educación religiosa, sino también intentó desmantelar la obra que Vasconcelos había hecho en la SEP y de la cual ella participara. ${ }^{37}$

José Vasconcelos fue empujado al exilio por los sonorenses, sus enemigos políticos en el poder desde 1924 y particularmente por su principal líder: Plutarco Elías Calles. Pero en 1929 intentó ser presidente de la República en una bullada campaña que constituyó un postrer intento de dar continuidad a una tendencia política que había iniciado con el antirreeleccionismo de Madero en 1909. Este contingente "vasconcelista", constituido por estudiantes y jóvenes intelectuales había dado lo mejor de sí con la campaña de alfabetización y la creación de la SEP. Gabriela Mistral lo acompañó, desde lejos, en esta aventura política.

35 Artículos periodísticos de Gabriela como el citado: “¿Cómo se ha hecho una escuela-granja en México" (diciembre de 1922); y otros como "Álvaro Obregón, presidente de México" (14 de abril de 1923), o "El presidente Obregón y la situación de México" (mayo de 1923), y "Desde México: el día de las madres” (junio de 1923), buscaban sacar de la percepción chilena la imagen de un México violento y convulsionado y mostrar la complejidad de su cultura.

36 Mistral, Lecturas para mujeres, México, Secretaría de Educación Pública, 1923.

37 Mistral, "La Escuela Nueva en Nuestra América”, Amauta, núm. 10, 1927, pp. 4-6. Citado en: Leonora Reyes, Movimientos de educadores y construcción de política educacional en Chile. (1921-1932 y 1977-1994), tesis doctoral, Universidad de Chile, 2005, pp. 71 y 112113. 
La posterior evolución del ex ministro hacia el nazismo, cuando publicó la Revista Continental Timón, entre febrero y junio de 1940, profundizó este distanciamiento. Gabriela, lo hemos visto en ese artículo de 1928, siguió siendo sufragista, agrarista y tolstoiana. Sin embargo, ambos continuaron su relación de respeto mutuo, aunque distante. Mientras la poetisa se despedía de su colaboración con la Unión Panamericana, el organismo internacional que dirigía el país que nunca pudo odiar dejaba ver que su pensamiento educativo había traspasado las fronteras nacionales y aún, continentales:

Nosotros debemos unificar a nuestras patrias por medio de una educación que se transmute en conciencia nacional y de un reparto del bienestar que se nos vuelva equilibrio absoluto; y debemos unificar esos países nuestros dentro de un ritmo acordado un poco pitagórico, gracias al cual aquellas veinte esferas se mueven sin choque, con libertad y, además, con belleza. Nos trabaja una ambición oscura y confusa todavía, pero que viene rodando por el torrente de nuestra sangre desde los arquetipos platónicos hasta el rostro calenturiento y padecido de Bolívar, cuya utopía queremos volver realidad de cantos cuadrados. Pero tenemos que comenzar con el Bien para acabar con la Belleza. Todos los bienes a medias o torcidos como el totalitarismo, aunque salgan de cunas clásico-cristianas acaban en Gorgonas o esperpentos. ${ }^{38}$

Hacia 1947, cuando Gabriela era Cónsul de Chile en Santa Bárbara, California, Vasconcelos le respondió una carta a propósito de un Congreso de Bibliotecarios realizado en Washington — comunicación que había recibido de manos de Palma Guillén-, donde lamentaba no haber asistido y tener la oportunidad de verla. ${ }^{39} \mathrm{El}$ ateneísta era director de la Biblioteca Nacional desde 1940. Pero, a pesar de la comunicación, en ese momento las relaciones entre ambos eran tensas: cuando Gabriela residió en Veracruz, invitada especialmente por el presidente Miguel Alemán como reconocimiento por su labor hacia la educación mexicana, la esposa de Vasconcelos acudía a visitarla, pero él se quedaba en la Ciudad de México. ${ }^{40}$

38 Mistral, "Sobre la Unión Panamericana", junio de 1946, Archivo del Escritor, Santiago, DIBAM.

39 “José Vasconcelos a Gabriela Mistral”, México, 23 de junio de 1947, en Sergei I. Zaïtseff, “Cartas de José Vasconcelos a Gabriela Mistral y Carlos Pellicer”, Casa del Tiempo, núm. 25, noviembre de 2009, México, UAM, p. 34.

40 La redacción, “Al final, tensión entre Vasconcelos y Gabriela Mistral”, Proceso, 11 febrero, 2007. Aunque la correspondencia entre ambos indica que, hacia 1953, la relación había retomado el afecto e intercambiaban opiniones sobre la labor bibliotecaria del ateneísta. "José Vasconcelos a Gabriela Mistral” (17 de enero de 1953), en Zaïtseff, “Cartas de José Vasconcelos a Gabriela Mistral y Carlos Pellicer”, p. 35. 
Un Congreso de escritores en 1953 los reunió por última vez en La Habana. Tres años después, en junio de 1956, el ateneísta continuaba dirigiendo la institución y escribía lo que tal vez fue la última comunicación entre ambos. Lo hacía con un dejo de amargura, lamentándose por el mundo que le dejaría a sus hijos y nietos: "en fin, Gabriela, pronto nos veremos por la otra vida". ${ }^{41}$ La "chilena errante" murió en Nueva York pasados seis meses, en enero de 1957. El ministro, ya rehabilitado intelectualmente en su país, la seguiría a la "otra vida” dos años después.

\section{LA UNESCO Y LA DIFUSIÓN UNIVERSAL DE LA EDUCACIÓN}

Los intentos del Instituto de Cooperación Intelectual por promover una cultura de la paz, a través del prestigio de escritores y artistas, fracasaron cuando en 1939 sobrevino una nueva conflagración mundial. De todos modos fue la organización internacional la cual concitó formalmente a más países para promover una cultura pacifista. Hubo que esperar a que finalizara la guerra para crear no sólo una nueva organización cultural, sino también una nueva organización multilateral que abarcara más países y promoviera un equilibrio más duradero entre las naciones del mundo. A partir de 1946, con la creación de la UNESCO, México consolidó la proyección internacional que había empezado con el Instituto Internacional de Cooperación Intelectual y nuevamente Jaime Torres Bodet estuvo a la cabeza de este proceso.

Jaime Torres Bodet, el joven intelectual quien, junto a Palma Guillén, recibiera a Gabriela en el puerto de Veracruz en 1922, ahora un ex ministro de educación y un diplomático de carrera de vasta experiencia, asumió la Dirección General de las Organización de las Naciones Unidas para la Educación, la Ciencia y la Cultura, UNESCO para el período de 1948 a 1952. Llegó precedido de ser "El hombre que enseñó a leer a 1,300.000 mexicanos”, y con el objetivo de iniciar una campaña de alfabetización mundial. De viaje a Beirut para asumir su cargo, fue recibido en París en forma apoteósica: conferencias, homenajes, cenas, discursos y cátedras estuvieron entre las muchas actividades que giraron en torno a su nombramiento. ${ }^{42}$

Desde su cargo mantuvo una nutrida correspondencia con la chilena. En el momento mismo de su nombramiento, le envío una extensa car-

41 “José Vasconcelos a Gabriela Mistral”, (junio de 1956), en Zaïtseff, “Cartas de José Vasconcelos...”, p. 36.

42 AHUNAM, Fondo Jaime Torres Bodet, "El hombre que enseñó a leer a 1,300.000 mexicanos, declara que París es la ciudad ideal por la defensa de inteligencia humana", "La campaña de alfabetización mexicana puede llevarse al mundo entero, dice Torres Bodet”; Recortes de Periódico/UnESCO, 1948, vol. 297. Recortes de Periódico/ UNESCO y 1949, vol. 299. 
ta de 23 páginas a Mérida, Yucatán — donde se encontraba temporalmente la poetisa-, contestándole otra, del día anterior, en que ella le hacía recomendaciones sobre la actitud que el gobierno de México debía tener ante los tratados de paz que se deberían firmar con los países vencidos en la Segunda Guerra Mundial. La misiva contenía una serie de documentos mecanografiados: Un discurso ante la ONU, dos entrevistas a la prensa y dos transcripciones que detallaban las propuestas de paz de México que presentaron y que fueron aprobadas por la organización. El alto funcionario mexicano le contestó comentándole aspectos delicados de la política internacional Mexicana. ${ }^{43}$ Pero ¿Cuál era el papel de Gabriela Mistral y otros intelectuales en el contexto del fin de la guerra y de formación de las naciones Unidas? Torres Bodet se lo señalaba así en otra carta:

...si la UnESCo logra suscitar la confianza de las masas a través de la difusión de los ideales por la acción de los grupos selectos que deben servir de puente entre la organización y los pueblos mismos. He aquí una empresa que escapa a las iniciativas oficiales pero que, recogido el germen de ella por espíritus como el suyo, podrá incitar a muchos escritores, maestros, artistas y sabios a constituir núcleos populares de "amigos de la Unesco", en los cuales -ya sea directamente, ya por conducto de las Comisiones Nacionales donde éstas realmente funcionen- contribuirán a afianzar la obra de nuestra Agencia en su baluarte, más firme: el corazón de los hombres de buena fe. ${ }^{44}$

En 1949, estando en París, el mexicano le envío (a ella y a otros intelectuales del continente) el informe del organismo explicándole que estaba interesado en que "personalidades latinoamericanas" lo conocieran y le hicieran sugestiones que recibiría "con el mayor gusto". ${ }^{45}$ En otra misiva se dirigía a la chilena como "mi muy querida amiga" para coordinar la posibilidad de que ésta asistiera a la Conferencia General de la UNESCO a celebrase en Florencia, Italia, en mayo de 1950. Aunque Chile aún no era parte del organismo, estaba en posibilidad de acreditar agregados y el mexicano albergaba el deseo de que Gabriela, quien se encontraba en una segunda estada en México, fuese enviada por su país en esa calidad:

43 “Jaime Torres Bodet a Gabriela Mistral”, México, 15 de noviembre de 1948, AE, exp. 8345.

44 “Jaime Torres Bodet a Gabriela Mistral”, París 20 de diciembre de 1948, AE, exp. 8347. f 1.

45 “Jaime Torres Bodet a Gabriela Mistral”, París, 3 de marzo de 1949, AE. 
Su viaje la alejará materialmente de México... pero estoy convencido de que, si mis compatriotas pierden el beneficio de su presencia física, no perderán jamás el estímulo de su conciencia humana. Me lo demuestra su propia carta, tan cargada de emoción y de amor fraternal para nuestros indios, cuyos problemas siento tan hondo en mi pensamiento y en mi corazón ¿Qué hacer, en efecto, para que la educación fundamental no implique un desencastamiento dañino y una invasión inútil, cuando no peligrosa, por brusca y por ignorante? He aquí la cuestión más profunda en todo lo que la UNESCO intenta en esta materia. ${ }^{46}$

El director general de la UNESCO retomaba los viejos motivos que habían caracterizado la obra educativa vasconcelista: regeneración social, educación indígena, inclusión en la nación moderna, etcétera, y reafirmada los principios del Congreso de Pátzcuaro de 1940, donde se había diseñado una nueva política de respeto a la identidad y la cultura indígenas. ${ }^{47}$ Pero, como autoridad al mando de una institución supranacional y con la misión de crear instituciones educacionales, Torres Bodet advertía a su ilustre amiga:

Creo que la respuesta no será nunca una respuesta doctrinaria, sino el resultado de una acción concreta, sobre el terreno, y de una acción que, aunque inspirada en principios universales, encuentre modos flexibles, sencillos y justos de adaptarse a lo regional. De ahí [que] me parezca tan importante la experiencia que nos proponemos llevar a cabo mediante la instalación de un Centro regional de formación de educadores de base y de preparación de material educativo audiovisual. ${ }^{48}$

El proyecto del “contemporáneo” era muy ambicioso y fue el que se implementó en Pátzcuaro, Michoacán, como el Centro Regional para la Educación, que tenía como misión preparar especialistas en el área. ${ }^{49}$ Pero lo notorio es que escribía en este tono pragmático a una de las principales representantes del "espiritualismo educativo”. El estilo pragmatista caracterizó a su generación, que "superó” el "espiritualismo” de las generaciones precedentes: la del Centenario o del Ateneo de la Juventud (1910), y la de los

46 “Jaime Torres Bodet a Gabriela Mistral”, París, 2 de febrero de 1950, AE, f. 8356.

47 Autoras como Celicia Greaves sostienen que, pese a lo acordado en el citado congreso, el proyecto de la élite mexicana de la década de 1940 seguía siendo el de una "sociedad culturalmente homogénea”, Greaves, "En busca de la Modernidad, 1940-1970”, en SEP noventa años, p. 45.

48 “Torres Bodet a Gabriela Mistral”, París, 2 de febrero de 1950, AE, exp. 8356.

49 Torres Septién (comp.), Pensamiento educativo de Jaime Torres Bodet, México, Secretaría de Educación Pública, Ediciones El Caballito, 1985, p. 11. 
"Siete sabios" (1915) y que ascendió rápidamente a altos puestos en la administración posrevolucionaria. ${ }^{50}$

En abril de 1951 Torres Bodet le respondía a su "muy querida amiga" una consulta sobre el carácter del Fondo de las Naciones Unidas para la Infancia, UNICEF, y sus atribuciones. La referida era una carta personal, pero le entregaba información de carácter oficial en forma detallada y se señalaba que además de las sedes existentes, pronto se instalaría una en Chile. ${ }^{51} \mathrm{Ga}$ briela, pese a los años y la distancia, no se olvidaba de uno de los motivos de su labor pedagógica y diplomática: los niños.

En marzo de 1952 Mistral contestaba una carta de Torres Bodet desde Nápoles, Italia, donde le contaba estar escribiendo un texto sobre los maestros rurales. Le comentaba al alto funcionario mexicano de la pena que le daba que las circulares que se producían en la UNESCO no tuvieran la posibilidad de llegar a los profesores chilenos. La poetisa indirectamente señalaba la distancia política con el gobierno de su país y criticaba el hecho de que aún no ingresara al organismo. En ese momento Chile era gobernado por Gabriel González Videla, quien había desatado una fuerte represión hacia los trabajadores ferroviarios e ilegalizado al Partido Comunista, mediante la Ley de Defensa de la Democracia, hecho por el cual su antiguo discípulo, el poeta Pablo Neruda, se había refugiado en México. ${ }^{52}$

\section{LA EXPANSIÓN DE LAS CAMPAÑAS ALFABETIZADORAS}

Para la década de 1960 México era uno de los países del mundo con más experiencia en campañas alfabetizadoras. En el transcurso de cuarenta años, la SEP había implementado tres grandes campañas con resultados diversos. La primera, desarrollada entre 1920 y 1924, fue encabezada por Vasconcelos, incluso antes de la creación del organismo, y tuvo resultados muy cues-

50 Investigadores como Bruno Jofré y Martínez valle han propuesto el concepto de "espiritualismo" para caracterizar la corriente pedagógica del vasconcelismo educativo. Véase: Rosa Bruno-Jofré y Carlos Martínez Valle, como "Ruralizando a Dewey: El amigo Americano, la colonización interna y la Escuela de la acción en el México posrevolucionario (19211940)", Encuentros sobre Educación, vol. 10, otoño 2009, pp. 43-64.

51 “Jaime Torres Bodet a Gabriela Mistral”, París, 3 de abril de 1951, AE, exp. 8356.

52 El Gobierno de González Videla (19456-1952) se desarrolló en medio de un recrudecimiento de la "guerra fría". El presidente ganó las elecciones de la mano de la izquierda comunista y socialista, incluso los primeros participaron de su gabinete, durante este período se les otorgó derechos políticos plenos a las mujeres. Pero presionado por Estados Unidos giró a la derecha, rompió relaciones con la Unión Soviética y persiguió a los comunistas, ilegalizándolos y formó un gabinete de liberales y conservadores. Para una historia de ese período véase Huneeus, La guerra fría chilena: Gabriel González Videla y la ley maldita, Santiago, Debate, 2009. 
tionados. Esto, debido a que no existen datos certeros sobre la cantidad de alfabetizados y por la ausencia de estadísticas oficiales centralizadas y modernas. Las únicas cifras son los cálculos de la propia SEP, publicados en su Boletín oficial. En 1922 el informe del presidente Obregón hablaba de unos 52.000 alfabetizados ese año; pero el Informe final, a cargo de la experimentada maestra Eulalia Guzmán sostiene que para 1923 se había alfabetizado un total de 37.000 personas. ${ }^{53}$ Este esfuerzo alfabetizador, por ser el primero, enfrentó numerosas dificultades, como la deserción y el desinterés de los educandos, la descoordinación entre maestros voluntarios y la dirección de la campaña, aparte de que la Secretaría de Educación vio reducido su presupuesto en un 50\% el último año de 1924, y que este último año la campaña había pasado a ser parte del Departamento Escolar de la SEP. Aunque las cifras son dignas de revisarse detalladamente (el informe de Guzmán al parecer no incluye los resultados de la campaña al mando de la Universidad), lo destacable es el enorme esfuerzo de experimentación que se llevó a cabo y la capacidad que mostró, primero la Universidad Nacional y luego la SEP, para movilizar a un enorme y variado contingente de alfabetizadores improvisados que se desplegaron por diversas localidades del país. ${ }^{54}$ Pero un elemento menos perceptible por las investigaciones realizadas es esta primera campaña alfabetizadora, misma que dejó un gran contingente de voluntarios, maestros y funcionarios educacionales de diversos rangos con una enorme experiencia organizativa que, al menos, estaba consciente de los errores cometidos, así como de los logros obtenidos.

La segunda campaña estuvo a cargo de Jaime Torres Bodet, secretario de educación entre 1943 y 1946, durante la presidencia de Manuel Ávila Camacho (1940-1946). Torres Bodet, como secretario particular del ministro Vasconcelos, había conocido desde adentro la primera campaña, por lo que después de dos desastrosas administraciones de la SEP en tres años: Luis Sánchez Pontón, 1940-1941, partidario de la educación socialista y luego la del conservador Octavio Véjar Vázquez, 1941-1943 y enemigo del izquierdismo en el sistema educativo, en especial de los sindicatos, debía levantar de nuevo la institución. Torres Bodet impulsó una reinterpretación del artículo $3^{\circ}$ de la Constitución que había establecido la "educación socialista" como política oficial del Estado mexicano, y aunque no le cambió el nombre, se suprimió la educación mixta, el campo dejó de ser el foco de atención

53 Guzmán, “Informe final de las labores desarrolladas bajo la dirección de la Campaña contra el analfabetismo durante el presente año 1923”, Boletín de la SEP, pp. 625-633. Fell, José Vasconcelos, pp. 45-46.

54 El desarrollo de esta primera campaña contra el analfabetismo puede verse en el Boletín de la Universidad, después Boletín de la Secretaría de Educación Pública. AHUNAM, Boletín de la SEP, 1920-1924. 
y el objetivo se reorientó hacia lo urbano y la industrialización, además se privilegió un sentido nacionalista y conservador: "Formar buenos ciudadanos, conscientes de sus derechos y obligaciones, respetuosos de la ley y leales a México, fue la consigna que sustituyó a la lucha de clases”. Torres Bodet se dio a la tarea de reorganizar la secretaría y de emprender una nueva campaña alfabetizadora con el fin de poner a México a la altura de los niveles educativos internacionales. ${ }^{55}$ Otras realizaciones del período fueron la creación de una emisora - Radio Educación-, la Escuela Nacional de Artes Plásticas y el Instituto de Alfabetización en Lenguas Indígenas. Por otro lado, una Comisión Revisora y Coordinadora de Planes Educativos trabajó permanentemente y llevó a cabo programas de estudio y textos escolares que imprimieron las cartillas "México", destinadas a la enseñanza de la lectura y escritura, entre otras muchas iniciativas.

El secretario Torres Bodet informó regularmente de los avances y problemas de la dependencia a su cargo. Aun así, el presupuesto para 1946 fue considerado insuficiente "para la campaña de alfabetización y [los] planes para crear nuevas escuelas y formar nuevos maestros". El analfabetismo era el más temible de los enemigos internos, que según cifras del momento, afectaba al 55\% de la población mayor de seis años. ${ }^{56}$ En la primera campaña contra el analfabetismo se apeló a la voluntad de las clases medias urbanas, ahora había un aire impositivo: la ley pretendía imponer que "todo mexicano mayor de 18 años y menor de 60 , que sepa leer y escribir y que no esté incapacitado, deberá enseñar a leer y escribir por lo menos a un analfabeto". ${ }^{57}$

El 21 de agosto de 1946, a tres años de promulgada y casi al finalizar su mandato, el secretario encabezó la celebración de los logros de la Ley de emergencia contra el analfabetismo, el nombre oficial de su campaña. Pese al esfuerzo, los resultados eran de dulce y agraz: según las cifras del censo de 1940 el número total de analfabetos era de 9.411.000.58 De esos, 2.250.000 estaban "excluidos de la obligación de aprender" (eran adultos);

55 Greaves, "En busca de la modernidad, (1949-1970)", en SEP Noventa Años, 1921-2011. Cimientos de la Nación, México, SEP, 2011, pp. 37-39.

56 AHUNAM. Fondo Jaime Torres Bodet, “Secretaría de Educación Pública, 1944-1945”, vol. 66, 176 Folios.

57 Greaves, “En busca de la modernidad”, p. 39 y Valentina Catón y Boris Beregson, "Noventa años de educación en México. Planes educativos y concepciones pedagógicas”, en SEP Noventa Años, p. 81.

58 Para la época, Wilkie ha dado cifras de alfabetización de 45.7\%, es decir, el analfabetismo afectaba al 54.3\% de la población mayor de 10 años. Aunque el mismo Torres Bodet en sus Memorias acepta que para el trienio 1944-1946 los analfabetos eran más que las cifras oficiales del Censo de 1940. Véase: Wilkie, La revolución mexicana, p. 541; Cfr. Torres Bodet, Memorias, p. 445. 
restaban 7.171.000, de ellos 1.237.000 eran indígenas monolingües, sujetos a métodos de enseñanza diferentes: primero tenían que leer y escribir en su lengua madre y luego alfabetizarse en castellano. 5.924.000 estaban sujetos a "los términos de la ley", es decir, a la obligatoriedad. En 17 meses de campaña fueron "atendidos” 1.441.794, de los cuales 708.657 habían presentado ya "examen satisfactorio", los restantes 732.137 "seguían normalmente su aprendizaje" ${ }^{59}$ La eficiencia de la instalación del sistema puede verse en los gastos que la Federación tuvo que erogar en la campaña alfabetizadora; éstos habían ascendido a 2.722 .525 pesos de la época, lo que equivalía a menos de $\$ 4$ por alfabetizado. Pese a esta buena señal, el alto funcionario admitía que "los resultados que aquí consigno eran muy inferiores a los que pretendíamos alcanzar, pero superiores a los que llegué a temer en mis días de desaliento". ${ }^{60}$

La tercera campaña alfabetizadora fue la más prolongada y masiva. Se desarrolló en el sexenio de 1958 a 1964, durante la presidencia de Adolfo López Mateos, y estuvo, desde el principio, bajo el comando de Torres Bodet, quien la asumió precedido de casi cuatro décadas de experiencia y de haber estado también, entre 1948 y 1952, al mando de la UNESCO, el principal organismo mundial abocado al tema. Esta campaña estuvo inmersa dentro de un plan mucho más integrador y ambicioso: el "Plan de los once años”: una planificación integral del sistema educativo y sus proyecciones, inédito para la cultura política e institucional mexicana. El Plan Nacional para el Mejoramiento y la Expansión de la Educación Primaria en México o "Plan de los Once Años" fue un intento inédito por diseñar la educación a mediano plazo para atender el rezago educativo y la creciente demanda escolar. Tenía como fundamentos los textos del educador chileno Guillermo Labarca y un plan de mejoramiento de la educación primaria propuesto por la UNESCO en 1956, para los países latinoamericanos y los Estados Unidos. ${ }^{61}$ Torres Bodet también revitalizó algunos antiguos proyectos vasconcelistas, como las misiones culturales; a la vez que, enfocado en la educación técnica, modernizó los Centros de Capacitación para el Trabajo Industrial y para el Trabajo Agrícola. ${ }^{62}$

Para 1959 la prensa celebró la distribución de libros de texto gratuitos y destacó la necesidad de formar entre cinco y ocho mil maestros más y de

59 Jaime Torres Bodet, Memorias, vol. I, México, Porrúa, 1981, p. 445. Las cifras de alfabetización varían y es necesario un análisis más profundo. Cfr. Latapí, "El pensamiento educativo de Torres Bodet: una apreciación crítica”, Revista Latinoamericana de Estudios Educativos, XXII: 3, 1992, p. 15.

60 Torres Bodet, Memorias, vol. I, p. 445.

61 Torres Bodet, "Plan de once años", Memorias, p. 78.

62 Latapí, "El pensamiento educativo de Torres Bodet”, p. 18. 
expandir la educación normalista e indígena. ${ }^{63}$ En sus Memorias, el ministro detalló los enormes problemas que debieron enfrentar para determinar el número de niños a los que había que llegar con la campaña alfabetizadora, cifra que variaba enormemente dependiendo de las estadísticas que manejara cada dependencia del gobierno federal. ${ }^{64}$ Aunque no faltaron los enemigos tradicionales a los planes educativos del gobierno, especialmente quienes se oponían al "texto único" (los manuales educativos distribuidos por el gobierno) —oposición a la que el secretario respondió en duros términos- es innegable el avance alfabetizador en estos seis años de mandato. ${ }^{65}$

Uno de los momentos más importantes de esta campaña alfabetizadora fue la Conferencia de 1962, celebrada en octubre en Roma. Entonces Torres Bodet envió a un "producto" de la escuela tolstoiana que se había formado en los primeros años de la revolución educativa: el entonces niño José Ávila Garibay ahora era director general de Alfabetización y Educación Extraescolar de la SEP y, como tal, elaboraba los informes para la UNESCO sobre la "Campaña contra el analfabetismo de adultos y jóvenes fuera del sistema escolar”. ${ }^{66}$ Éste había aprendido tanto sus primeras letras como diversas tareas agrícolas y cooperativas en la escuela símbolo de la SEP: la Escuela Granja Francisco I. Madero, usando los métodos paidocéntricos, intuitivos y experimentales de la "escuela nueva o de la acción". Ávila continuó en la Escuela Normal y una vez egresado retornó a sus antiguas aulas como maestro; en pocos años escaló hasta ser nombrado director y durante la administración de Lázaro Cárdenas colaboró para transformar a La Madero en una escuela industrial y volver al magistocentrismo y la planificación, lo que significó olvidar los principios tolstoianos y tagoreanos, bajo los cuales se había formado. ${ }^{67}$ Ávila continuó trabajando e hizo sus propios aportes al nuevo sistema educativo que se abría paso fácilmente entre los dirigentes de la SEP y el Estado, con la anuencia de los presidentes de turno y difícilmente en las escuelas rurales, donde eran aplicados concretamente. El joven profesor elaboró un libro sobre la escuela que dirigía explicando los cambios que había aplicado el gobierno cardenista y la construcción del nuevo edificio y sus modernas instalaciones y talleres; también escribió sobre el "método de

63 AHUNAM. Fondo Jaime Torres Bodet, "Recortes de Periódico/Secretaría de Educación Pública”, 1959, vol. 274.

64 Torres Bodet, Memorias, pp. 77-94.

65 AHUNAM, Fondo Jaime Torres Bodet, “El gran programa educativo”, Recortes de Periódico/Secretario de Educación Pública, 1963, vol. 281.

66 "UNESCO. Informe de la Campaña contra el analfabetismo de adultos y jóvenes fuera del sistema escolar”, México, D.F., 4 de abril de 1964, en ASRE, núm. 1204.

67 "Opiniones sobre la labor sanitaria aquí y sobre el analfabetismo", El Universal, 23 de septiembre de 1962. 
jornadas", sistema basado en el "método de proyectos" del educador Kilpatric, discípulo de John Dewey, pero inspirado en el nacionalismo mexicano, ahora la única corriente educativa oficial. ${ }^{68}$ Ávila continuó trabajando y en la década de 1980 llegó a ser pionero en la "educación vial”, destinada a la educación de los habitantes de la Ciudad de México ante los graves problemas derivados del crecimiento urbano.

En la Conferencia de Roma, Ávila llevó la representación de México donde expuso sobre la campaña alfabetizadora que se desarrollaba en ese momento en el marco del Plan de Once Años. ${ }^{69}$ Su experiencia concreta en la Escuela Madero, en la alfabetización y el apoyo de Torres Bodet lo llevaron ser Director General de Alfabetización y Educación Extraescolar, puesto en el que relacionó directamente con la UNESCO con la que colaboró enviando informes sobre el avance de la campaña en México. ${ }^{70}$

En la década de 1960 Chile y México fortalecieron sus relaciones en el espacio de la UNESCO, donde Silvio Zavala, por México y Juvenal Hernández, por Chile, eran los representantes oficiales. Una nueva generación había tomado la posta que dejaran Vasconcelos y Mistral. ${ }^{71}$ En marzo de 1962 se celebró en Santiago de Chile la Conferencia sobre Educación y Desarrollo Económico y Social en América Latina; la reunión de París de ese mismo año invitó a los Estados Miembros de América Latina a aplicar las recomendaciones sobre planeamiento de la educación aprobadas en marzo.

Para ese mismo 1962 la extensa experiencia de México en las campañas alfabetizadoras estaba consolidada e institucionalizada en el sistema internacional. Entonces la Conferencia Regional de la UNESCO, celebrada en París,

68 Ávila Garibay, La Escuela Francisco I. Madero y El método de jornadas aplicado a la escuela primaria, México, DIEP, Cooperativa Talleres Gráficos de la Nación, 1944. William H. Kilpatrick, Nació en Georgia, USA en 1871. Fue discípulo y colaborador de John Dewey. Estudió en Mercer, John Hopkins y Columbia. Fue maestro de escuela y del Teachers College de Columbia. Fue promotor del "método de proyectos" que planteaba que la educación debe servir a los estudiantes para reconstruir o reorganizar su experiencia, para que puedan contribuir a la vida social en un sentido amplio. Murió en 1965 en Nueva York. Díaz Barriga, Enseñanza situada: Vínculo entre la escuela y la vida, México, McGraw Hill, 2005.

69 “Elogian 80 países nuestra campaña alfabetizadora”, El Universal, México, 1 de octubre de 1962.

70 UNESCO. "Informe de la Campaña contra el Analfabetismo entre adultos y jóvenes fuera del sistema escolar”, Reuniones Comité Consultivo Internacional de Enlace, Alfabetización y otras reuniones relacionadas con la materia, Dirección de Asuntos Culturales, 1964-1968. México, 4 de abril de 1964.

71 Juvenal Hernández Jaque (1899-1979) fue rector de la Universidad de Chile entre 1933 y 1953, durante su mandato se creó la Comisión de Cooperación Intelectual, por lo que es normal que, pese a que había dejado la rectoría hacía 9 años, fuera el representante de Chile ante la UNESCO. Silvio Zavala (1909-2014), por su parte, Entre 1956 y 1963 fue delegado permanente de México en la UNESCO, en París. 
en el marco del Proyecto principal sobre extensión y mejoramiento de la educación primaria en América Latina, aprobó:

...utilizar en la mayor medida posible los servicios del Centro Regional de Educación Fundamental para el Desarrollo de la Comunidad de América Latina establecido en Pátzcuaro (México), así como los de sus graduados, en los programas nacionales de desarrollo de la comunidad y de educación de adultos y en las campañas de alfabetización que emprendan, especialmente para el planeamiento y ejecución de proyectos, la formación de personal y la producción de material didáctico. ${ }^{72}$

En el mismo documento se acordó prolongar por otros diez años el funcionamiento del Centro Regional — la aspiración de Torres Bodet- con el fin de fomentar la educación de los adultos y la descentralización del organismo estableciendo diversas funciones en distintos países del continente. ${ }^{73}$

\section{LA PERMANENCIA DE LAS IDEAS TOLSTOIANAS Y TAGOREANAS EN EL SISTEMA EDUCATIVO MEXICANO}

Las ideas tolstoianas y tagoreanas, promovidas por Vasconcelos y Gabriela Mistral, permanecieron en el sistema educativo mexicano y en muchos de sus funcionarios e intelectuales, pese al cambio ideológico que imprimió la élite posrevolucionaria mexicana al resto de la sociedad. A partir de 1940, los gobiernos privilegiaron el industrialismo por sobre el agrarismo, lo que se vio reforzado por la fuerte migración de campo a la ciudad en la década de 1960. Aun así, hacia fines de esta década la presencia y peso de los maestros rurales en el sistema educativo mexicano era considerable.

Aunque nunca fue un convencido de la viabilidad de las propuestas de Tolstoi en la educación, Jaime Torres Bodet siempre admiró la obra educativa del escritor ruso y, en alguna medida la aplicó cuando tuvo oportunidad. Ya en 1923 el joven secretario particular de Vasconcelos había escrito un texto en el que cuestionaba a Tolstoi expresado en una crítica al Emilio de Rousseau. ${ }^{74}$ Pero en 1965 , cuando el dos veces ministro y ex director de la UNESCO abandonó el servicio público, escribió la única biografía de Tolstoi en español. En ella dedicó varias páginas a hablar sobre el proyecto tolstoiano y su escuela experimental de Yásnaia Poliana. ${ }^{75}$

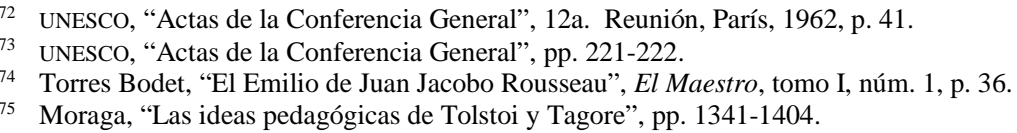


En su Tolstoi, Torres Bodet reflexionó sobre los aspectos más profundos de la concepción educativa del escritor ruso. Escrito en el formato biográfico tradicional, se centra en el autor de La guerra y la paz; sin embargo, en la parte sustancial del libro se alejó de la biografía y dedicó páginas fundamentales a reflejar su concepción y su experiencia sobre la educación. De hecho, el tema educativo escapa al objetivo biográfico del libro. Todo se produce en una parte central, cuando el ruso regresó a su natal Yásnaia Poliana con el propósito de sentar cabeza, cansado ya de una agitada vida de juveniles excesos sensuales. Allí era señor feudal de una gran propiedad rural y de mucha servidumbre; entonces se topó con una serie de niños, según Torres Bodet, "rústicos y locuaces":

\begin{abstract}
De su maestro Rousseau había heredado, junto con el amor de la naturaleza, una intención pedagógica muy marcada. Seguía siendo el Emilio uno de sus libros fundamentales. Además de Rousseau, había leído a Pestalozzi y a Froebel. Juan Jacobo patrocinó la doctrina: no hay programa que valga para todos los niños en general. La educación constituye un proceso personalísimo. ${ }^{76}$
\end{abstract}

Desde esta manera Jaime Torres Bodet fue partícipe crítico de la corriente "espiritualista" entre las diversas "pedagogías" impulsadas por el Estado mexicano entre 1921 y 1964. Su insistencia en la alfabetización, como principal herramienta de integración e inclusión social, la distribución de libros de texto gratuitos (política que hasta aún hoy se mantiene), su participación en tres campañas alfabetizadoras así lo demuestran.

\title{
CONCLUSIONES
}

José Vasconcelos fue uno de los intelectuales mexicanos más influyentes en el siglo pasado, tanto por el desarrollo de las ideas que pusieron fin al predominio de la cultura oligárquica, como su acción política durante la revolución y la posterior creación de la SEP. Gabriela Mistral fue la chilena que más contribuyó al acercamiento de ambos países en los dos siglos de vida independiente de éstos. Tanto el efecto que produjo la prolongada "experiencia mexicana” en su producción literaria, como la influencia que ella misma ejerció en la educación fueron profundos e intensos.

La amistad de Mistral con Vasconcelos y la élite intelectual mexicana de la primera mitad del siglo XX fue fructífera. No sólo el ateneísta, sino también Jaime Torres Bodet, Palma Guillén, el poeta y dirigente estudiantil

76 Torres Bodet, León Tolstoi, pp. 73-74. 
Carlos Pellicer y la radical educadora Elena Torres, entre muchos otros, fueron colaboradores y aliados en una batalla cultural y educativa que se prolongó más allá de sus ejercicios en secretarías de Estado, ministerios, direcciones, cargos diplomáticos y protagonismo en organismos internacionales.

Hasta hace algunos años poco se sabía de la acción concreta de Gabriela Mistral en México, a lo más se señalaba que había participado en las misiones culturales durante los años 1922 a 1924, editado un libros de lecturas y mantenido comunicación con su secretaria Palma Guillén y con Alfonso Reyes. De la segunda estancia se creía que, afectada de su salud, se había dedicado a descansar en Xalapa, sin poder viajar a la Ciudad de México, pero no se sabía nada de su nutrida e influyente actividad internacional a favor de la educación y la lectura, junto a Torres Bodet.

En este trabajo hemos analizado la fuerte y prolongada relación que mantuvo la poetisa chilena con México, después de ser parte de la SEP durante el mandato de Vasconcelos, a través del continuador indirecto de la obra vasconcelista, el poeta y diplomático Jaime Torres Bodet. Este alto funcionario fue el hombre más influyente en el sistema educativo mexicano: fue secretario particular de los dos ministros de educación de los primeros gobiernos posrevolucionarios, dos veces ministro de educación y director general de la UNESCO, además de diplomático acreditado en Francia, Argentina y otros países. Al mando de este organismo, Torres Bodet requirió los servicios y consejos de la universal poetisa y maestra rural, sobre los desafíos de la educación en el sistema internacional. Esto nos lleva a valorar mejor la influencia educativa de Mistral, ya que los estudios realizados hasta ahora sólo enfatizaban los primeros años de esta intelectual en México.

En estas líneas nos hemos introducido en un tema mucho más amplio, hay que hacer un trabajo más minucioso y enfocado para lograr aquilatar la influencia de las ideas educativas de Gabriela Mistral en México y en el sistema internacional que implementó la UNESCO a partir de 1946. Asimismo, es necesaria una reevaluación de la influencia de Vasconcelos para comprender mejor la compleja evolución del sistema educativo mexicano. Ello nos llevaría también a conocer de manera más precisa la permanencia y efectos concretos de ese proteico movimiento iniciado a fines del siglo XIX de la Escuela "Nueva o de la acción" y su legado en la segunda mitad del siglo XX, tanto en México como en el mundo: el enorme aporte a las campañas alfabetizadoras impulsadas por la UNESCO, cuyo protagonista fue el producto mejor logrado de los primeros años del vasconcelismo educativo: el maestro y educador José Ávila Garibay. 
A fines de la década de 1950 terminó el ciclo vital de una generación latinoamericana que había nacido durante los años de 1880 , pero que desarrolló su máxima potencia entre 1910 y 1950. Gabriela Mistral y José Vasconcelos, distanciados política y vivencialmente, murieron con dos años de diferencia. Pero ambos, desde su salida siguieron influyendo indirectamente a través de quien tomó la posta: Jaime Torres Bodet; su labor en la educación pública mexicana e internacional influyó por muchos años pese a las críticas y cambios que hicieron los gobiernos sucesivos y las nuevas generaciones intelectuales que heredaron el poder.

\section{FUENTES Y BIBLIOGRAFÍA}

Fuentes y Archivos

Archivo del Escritor, AE, Santiago.

Archivo de la Organización de las Naciones Unidas para la Educación la Ciencia y la

Cultura, Cultura, Actas de la conferencia General, "Resoluciones", $12^{\mathrm{a}}$ Reunión, París, 1962.

Archivo de la Secretaría de Educación Pública, ASEP, México.

Archivo de la Secretaría de Relaciones Exteriores, ASRE, México.

Archivo Histórico de la Universidad Nacional Autónoma de México, AHUNAM.

El Universal, México, 1920-1962.

El Maestro, Revista de Cultura Nacional, México, núms. 5 y 6, 1921-1923.

Repertorio Americano, San José, 1922-1925.

UNESCO. "Reuniones Comité Consultivo Internacional de Enlace, Alfabetización y otras reuniones relacionadas con la materia, Dirección de Asuntos Culturales, 1964-1968”. México, 4 de abril de 1968.

Libros

Ávila Garibay, José, La Escuela Francisco I. Madero y la Educación en México, México, Talleres Gráficos La Nación, 1940.

—_, El método de jornadas aplicado a la escuela primaria, México, DIEP, Cooperativa Talleres Gráficos de la Nación, 1944.

Cantón Arjona, Valentina y Aguirre Beltrán, Mario José, Revista “El Maestro” (1921-1923), Morelia, Instituto Michoacano de Ciencias de la Educación, 1997.

Cook, Katherine. La Casa del Pueblo. Un relato acerca de las escuelas nuevas de acción de México, México, SEP, 1936.

Díaz Barriga, Frida, Enseñanza situada: Vínculo entre la escuela y la vida, México, McGraw Hill, 2005. 
Fell, Claude, José Vasconcelos. Los años del águila, México, UNAM, 1987.

Frei, Eduardo, La Política y el espíritu, Santiago, Editorial del Pacífico, 1946.

Greaves, Cecilia, Del radicalismo a la unidad nacional: una visión de la educación en el México contemporáneo 1940-1964, México, El Colegio de México, 2008.

Guzmán, Eulalia, La escuela nueva o de la acción, México, Editorial Cultura, 1923.

Huneeus, Carlos, La guerra fría chilena: Gabriel González Videla y la ley maldita, Santiago, Debate, 2009.

Meneses Morales, Ernesto, Tendencias educativas oficiales en México 1911-1934, México, Universidad Iberoamericana, 1986.

Mistral, Gabriela, Lecturas para mujeres, México, Secretaría de Educación Pública, 1923.

, Pasión por enseñar. Pensamiento Pedagógico, Valparaíso, Ediciones de la Universidad de Valparaíso, 2017.

Pita González, Alexandra, Educar para la paz. México y la cooperación intelectual internacional, 1922-1948, México, Universidad de Colima-Secretaría de Relaciones Exteriores, 2014.

Quezada, Jaime, Gabriela Mistral: Escritos políticos, México-Santiago, Fondo de Cultura Económica, 1994.

Reyes, Leonora, Movimientos de educadores y construcción de política educacional en Chile. (1921-1932 y 1977-1994), Tesis doctoral, Universidad de Chile, 2005.

SEP, Bases para la organización de la escuela primaria, conforme al principio de la acción, México, talleres de la impresora, 1923.

SEP, SEP Noventa Años, 1921-2011. Cimientos de la Nación, México, SEP, 2011.

Sierra, Augusto Santiago, Las misiones culturales, México, Secretaría de Educación Pública, 1973.

Schell, Patience A., Church and state education in revolutionary Mexico City, Tucson, University of Arizona, 2003.

Tagore, Rabindranath, Shantiniketan. Morada de la Paz. La escuela de Rabindranath Tagore en Bolpur, Madrid, 1919.

Tolstoi, León, La escuela de Yásnaia Poliana, Barcelona, Olañeta, 1978.

Torres Bodet, Jaime, Memorias, vols. 1 y 2, México, Editorial Porrúa, 1981. -, León Tolstoi, México, FCE, 1965.

Torres Septién, Valentina (comp.), Pensamiento educativo de Jaime Torres Bodet, México, Secretaría de Educación Pública, Ediciones El Caballito, 1985.

Vasconcelos, José, La raza cósmica. Misión de la raza iberoamericana. Notas de viajes a la América del Sur, París, Agencia Mundial de Librería, 1925.

-, De Robinson a Odiseo, pedagogía estructurativa, Madrid, 1935.

—, Ulises criollo, México, Editorial JUS, 1979. 
El Desastre, Editorial JUS, FCE, 1979.

Zegers, Pedro Pablo, Gabriela y México, Santiago, RIL Editores, 2007.

Artículos

Bruno-Jofré, Rosa y Carlos Martínez Valle, como "Ruralizando a Dewey: El amigo Americano, la colonización interna y la Escuela de la acción en el México posrevolucionario (1921-1940)”, Encuentros sobre Educación, vol. 10, otoño, 2009 pp. 43-64.

Guillén, Palma, “Gabriela Mistral, 1922-1924”, Lecturas para mujeres, México, SEP, 1988.

Guzmán, Eulalia, “Informe final de las labores desarrolladas bajo la dirección de la Campaña contra el analfabetismo durante el presente año 1923”, Boletín de la SEP, pp. 625-633.

Herrera, Fabián, "México y el Instituto Internacional de Cooperación Intelectual 1926-1939”, Tzintzun, núm. 49 Morelia ene-junio, 2009.

Latapí, Pablo, “El pensamiento educativo de Torres Bodet: una apreciación crítica”, Revista Latinoamericana de Estudios Educativos, XXII: 3, 1992, pp. 13-44.

Luquín Guerra, Roberto, "La intuición originaria en la filosofía de José Vasconcelos”, Signos Filosóficos, VIII: 16, julio-diciembre, 2006, pp. 97-124.

Gómez Santana, Laura Guillermina, "Escuelas y enseñanza agrícola en Jalisco, 19201924”, X Congreso Nacional de Investigación Educativa, $<$ http://www.comie.org.mx/congreso/memoriaelectronica/v10/pdf/area_temat ica_09/ponencias/1407-F.pdf $>$.

Moraga Valle, Fabio, "Incluir para formar la nación la "Escuela Nueva” o de la “Acción” en el México Posrevolucionario, 1921-1964”, Cuadernos Chilenos de Historia de la Educación, núm. 7, julio, Santiago, 2017, pp. 9-46.

, “¿Una escuela tolstoiana para la revolución mexicana? La Escuela-Granja Francisco I. Madero de la Colonia La Bolsa, 1921-1940”, Pacarina del Sur, núm. 32, julio-septiembre, 2017.

$<$ www.pacarinadelsur.com/index.php?option=com_content\&view=article\&id $=1490$ \&catid $=10>$.

_ - "Las ideas pedagógicas de Tolstoi y Tagore en el proyecto vasconcelista de educación, 1921-1964”, Historia Mexicana, núm. 259, México, El Colegio de México, 2016, pp. 1341-1404.

—_ "Lo mejor de Chile está ahora en México. Ideas políticas y labor pedagógica de Gabriela Mistral en México, 1922-1924”, Historia Mexicana, núm. 251, México, El Colegio de México, 2014, pp. 1181-1248.

Quintanilla, Susana, “Por qué importa Vasconcelos”, Revista Mexicana de Investigación Educativa, COMIE, pp. 1294-1295. 
Redacción, “Al final, tensión entre Vasconcelos y Gabriela Mistral”, Proceso, 11 febrero, 2007.

Rojo de la Rosa, Grínor, “Gabriela Mistral y la reforma agraria chilena”, Anales de la Universidad de Chile, VII: 12, 2017.

Renoliet, J.J., L’UNESCO oubliée: la Société des Nations et la coopération intellectuelle, 1919-1946, Paris, Publications de la Sorbonne, 1999.

Romanell, Patrick, "Bergson in Mexico: A Tribute to José Vasconcelos”, Philosophy and Phenomenological Research, vol. 21, no. 4 (junio 1961), pp. 501-513.

Valderrama, Fernando, "La UNESCO y la Educación”, consultado el 11 de diciembre de 2017 en: <http://www.unesco.org/education/pdf/VALDERRA.PDF>.

Zertuche, Fernando, Jaime Torres Bodet. Realidad y destino, México, FCE, 2016.

Zaïtseff, Sergei I., “Cartas de José Vasconcelos a Gabriela Mistral y Carlos Pellicer”, Casa del Tiempo, núm. 25, noviembre de 2009, México, UAM, pp. 29-44. 